\title{
PRIMARY HEMANGIOMA OF THE SKULL
}

\author{
Baltazar Leão Reis¹, Gervásio Teles Cardoso Carvalho², Atos Alves de Sousa2, \\ Warley Barbosa de Freitas $^{1}$, Rafael Augusto Castro Santiago Brandão ${ }^{1}$
}

Hemangiomas are benign vascular tumors that may involve any part of the body. Primary osseous hemangiomas occur more frequently in the spine and less commonly in the skull. Toynbee $1845^{1}$ was the author of the first report in English, a case of hemangioma of the skull bones. We report a rare case of skull cavernous hemangioma that was considered initially as prostate tumor metastasis.

\section{CASE}

In February 2007, a 73-year-old white man had a sudden onset of dizziness and reading difficulty. He was on drug treatment for arterial systemic hypertension, and had undergone surgical treatment for prostate malignancy eight years previously, with seemingly adequate control. Computed tomography (CT) (Fig 1) and magnetic resonance imaging (MRI) (Fig 2) showed an ischemic area on the left occipital region and an intraosseous expansive lytic lesion on the right frontotemporal region, without signs of brain tissue involvement. There were no symptoms attributable to the osseous lesion. The hypothesis was a metastatic lesion from the prostate tumor.
In March 2007, he underwent right frontotemporal craniectomy with en bloc resection of the osseous lesion, followed by cranioplasty with acrylic cement.

Histopathology of the surgical sample showed primary osseous cavernous-type hemangioma.

\section{DISCUSSION}

Hemangiomas are benign vascular neoplastic disorders. Histopathology classifies hemangiomas as venous, cavernous, and capillary, according to the predominant vascular network ${ }^{2}$. Although cavernous hemangiomas more often involve the brain parenchyma, skull bones may also be affected. Intraosseous hemangiomas are relatively rare, and the spine is the most commonly involved site, followed by the skull bones. Hemangiomas of the skull represent $0.2 \%$ of all osseous tumors ${ }^{2-4}$, and $10 \%$ of all the benign tumors of the skull ${ }^{2,3}$.

In a review undertaken by Heckl and coworkers ${ }^{5}$, covering the period from 1975 to 2000, cavernous he mangiomas of the skull involved the frontal, temporal, and
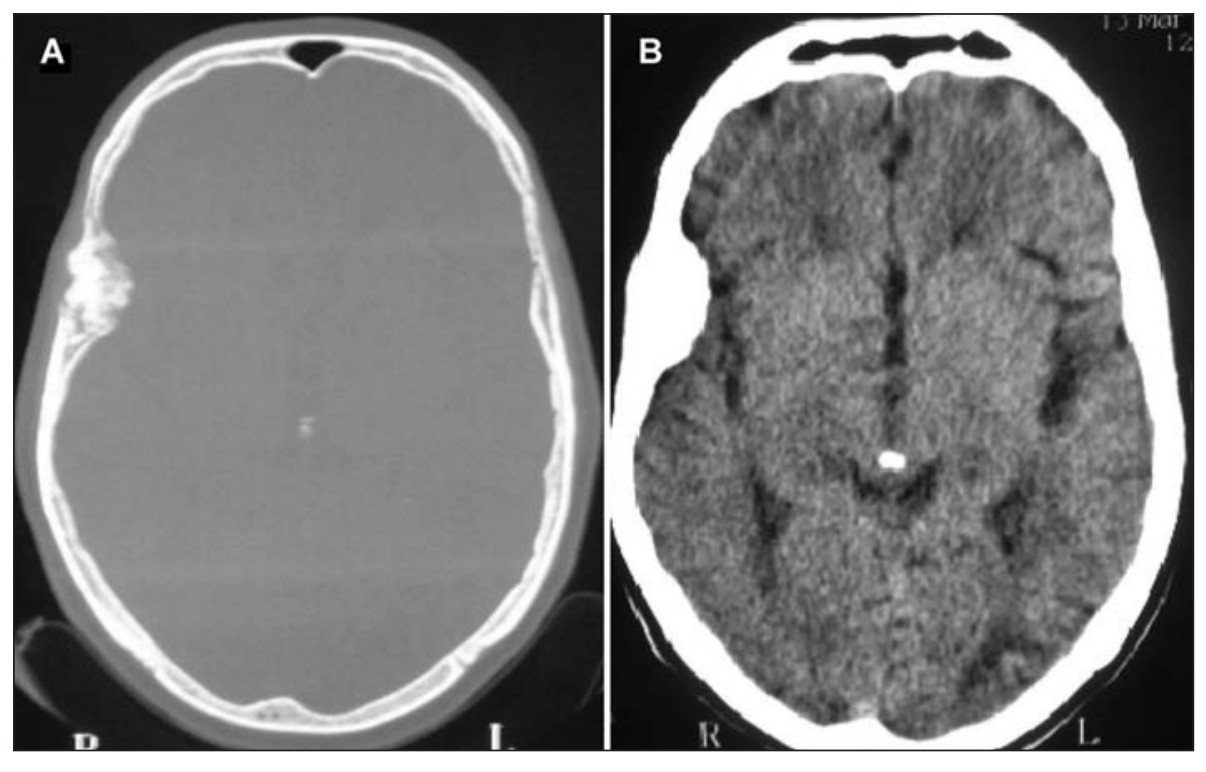

Fig 1. (A) Bone window CT showing "honeycomb" osseous lesion. (B) Preoperative CT showing an expansive intraosseous lesion on the right frontotemporal region, and an ischemic area on the left occipital region.

\section{HEMANGIOMA PRIMÁRIO DO CRÂNIO}

'Resident, Neurosurgery Service, Santa Casa de Belo Horizonte, Belo Horizonte MG, Brazil; ${ }^{2}$ MD, Neurosurgery Service, Santa Casa de Belo Horizonte and Faculdade de Ciências Médicas, Minas Gerais, Brazil.

Received 5 December 2007, received in final form 10 April 2008. Accepted 15 May 2008

Dr. Baltazar Leão Reis - Rua Romano Stochiero 34/701 - 30130-120 Belo Horizonte MG - Brasil. E-mail: baltazarleao@yahoo.com.br 
Fig 2. (A) Nonenhanced T7- weighted MRI showing a right frontotemporal osseous lesion and an ischemic area on the left occipital region. (B) Gadolinium-enhanced T7- weighted MRI showing heterogeneous uptake by the osseous lesion, a finding pointing to a vascular origin.
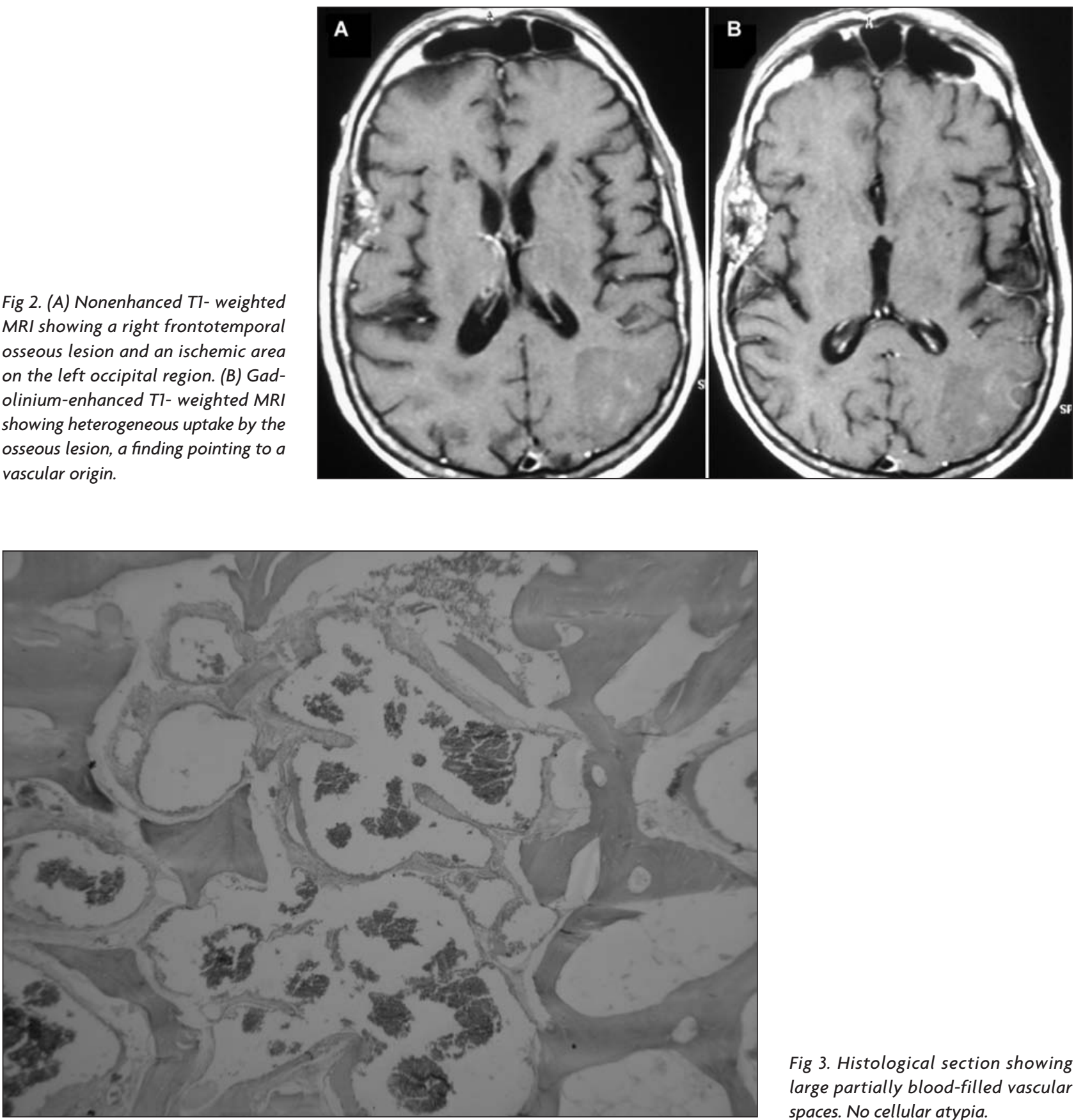

Fig 3. Histological section showing large partially blood-filled vascular spaces. No cellular atypia.

parietal bones, in decreasing order. In another review, undertaken by Barnes ${ }^{6}$ in 1985, the frontal bone was also the most frequently involved site, followed by the parietal bone and the zygomatic process.

Our patient had right frontotemporal involvement.

Although cavernous hemangiomas of the skull are more prevalent in middle-aged women ${ }^{2}$, the exact gender distribution has not been clearly established. Intraosseous cavernomas are extremely benign, slow-growing, mostly asymptomatic tumors ${ }^{2}$. The main complaint is an aesthetic embarrassment, sometimes a mass effect being present. Patients may rarely present with an associated epidural hematoma or subarachnoid hemorrhage 2 .

Hemangiomas tend to be solitary lesions, but there have been reports of widespread body involvement, a situation termed angiomatosis ${ }^{7}$.

Skull radiography usually shows lytic lesions with sclerotic borders and a "honeycomb" appearance"

$\mathrm{CT}$ is an excellent investigation, as it allows detailed characterization of the cortical and trabecular bone to be made ${ }^{8}$. Although the appearance on CT may vary, an expansive lesion with thin borders and intact internal and 
external skull plates is the most common finding ${ }^{8,9}$. According to Heckl and coworkers ${ }^{5}$ external plate erosion, associated with external tumor expansion, and preservation of he internal plate are the most common radiological findings. Yet, in our case there was obvious erosion of the internal plate, with more prominent tumor extension to the inside of the skull, but without any direct or indirect mass effect on the brain. The external plate was also eroded, but without significant alteration of the skull outline.

MRI investigation is important because of its potential to show soft tissue lesions ${ }^{9}$. MRI signal intensity depends on the amount of venous stasis in the lesion and also on the rate of transformation of red marrow into yellow marrow. While T1-weighted sequences may give high or low intensity signals, water-sensitive sequences, such as $\mathrm{T} 2$ and FLAIR, commonly give high intensity signals ${ }^{8}$. Banerji and coworkers $^{10}$, in 1994, suggested that early focal contrast uptake by the lesion, with subsequent diffusion to the entire affected area, would be characteristic of osseous angiomas. Because it can identify relative changes in the lesion blood flow (a vascular blush, for example), MRI may also suggest the vascular nature of the lesion" (Fig 2).

Cerebral angiography is important for surgical planning of smaller lesions and embolization of larger ones. Local vascularization increase and the feeding pedicles, without a large draining vein, may be identified ${ }^{5}$. In some cases, angiography fails to distinguish the feeding vessels, but when they are identified, the middle meningeal artery and the superficial temporal artery are the most commonly involved vessels ${ }^{2,12}$.

Although surgery is the treatment of choice, it is not always necessary. Indications for surgery include: correction of compressive effects, hemorrhage control, and aesthetic improvement ${ }^{8}$, besides cases like ours, in which a metastatic lesion is an important differential. En bloc resection of the lesion reduces the risk of bleeding, always potentially high in these tumors. Relapse is rare when adequate safety margins are observed. Curettage and irradiation are other therapeutic options. In most cases, isolated curettage does not afford full tumor removal, relapses being more frequent. This technique is also associated with excessive bleeding, besides making adequate hemostasis more difficult to achieve ${ }^{13}$. Radiotherapy must be considered when- ever surgical access is difficult and as a complement to subtotal resections ${ }^{14}$. In keeping with the most widely recommended technique, we opted for a craniectomy with en bloc resection, keeping a small safety margin. We then performed cranioplasty with acrylic cement.

On histopathology, cavernous hemangiomas consist of a well-defined, nonencapsulated mass, composed of large fully or partially blood-filled cavernous vascular spaces, separated by scant connective tissue. Intravascular thrombosis with associated dystrophic calcification may also be seen $^{3,7}$ (Fig 3).

In conclusions, primary osseous hemangioma of the skull is a rare benign lesion of vascular origin. Because the imaging findings are not specific, preoperative diagnosis is difficult, histopathology being essencial. Surgery is indicated to differentiate it from metastasis, or when there are aesthetic or compressive issues. En bloc resection must be attempted, because relapse is rare when this surgery is successful.

\section{REFERENCES}

1. Toynbee J. An account of two vascular tumors developed in the substance of bone. Lancet 1845;2:676.

2. Politi M, Romeike BF, Papanagiotou P, et al. Intraosseous hemangioma of the skull with dural tail sign: radiologic features with pathologic correlation. AJNR Am J Neurorradiol 2005;26:2049-2052.

3. Liu JK, Burger PC, Harnsberger HR, Couldwell WT. Primary intraosseous skull base cavernous hemangioma: case report. Skull Base 2003;13:219-228.

4. Sargent EN, Reily EB, Posnikoff J. Primary hemangioma of the skull case report of an unusual tumor. Am J Roentgenol 1965;95:874-879.

5. Heckl S, Aschoff A, Kunze S. Cavernomas of the skull: review of the literature 1975-2000. Neurosurg Rev 2002;25:56-62, discussion 66-67.

6. Barnes L. Solitary hemangioma of bone. In Barnes L (ed) Surgical pathology of the head and neck, vol 1. New York: Dekker 1985:932-936.

7. Cotran RS, Kumar V, Collins T. Robbins, pathologic basis of disease, $6^{\text {th }}$ Ed. Philadelphia: W. B. Saunders 1999.

8. Moore SL, Chun JK, Mitre SA, Som PM. Intraosseous hemangioma of the zigoma: CT and MR findings. AJNR Am J Neurorradiol 2001;22:1383-1385.

9. Amaral L, Chiurciu M, Almeida JR, Ferreira NF, Mendonça R, Lima SS MR imaging for evaluation of lesions of the cranial vault. Arq Neuropsiquiatr 2003;61:521-532.

10. Banerji D, Inao S, Sugita K, Kaur A, Kumar D. Primary intraosseous orbital hemangioma: a case report and review of the literature. Neurosurgery 1994;35:1131-1134.

11. Kumar S, Grupta S, Puri V, Mehndiratta MM, Malhotra V. Intradiploic hemangioma of skull bone. Indian Pediatr 1993;30:399-401

12. Bastug D, Ortiz O, Schochet SS. Hemangiomas in the calvaria: imaging findings. AJR 1995;164:683-687.

13. Peterson DL, Murk SW, Story JL. Multiple cavernous hemangiomas of the skull: report of a case and review of the literature. Neurosurg 1992;30:778-782.

14. Sweet C, Silbergeit R, Mehta B. Primary intraosseous hemangioma of the orbit: CT and MR appearance. AJNR Am J Neuroradiol 1997;18:379-381. 